\title{
A vaccine with $A \beta$ oligomer-specific mimotope attenuates cognitive deficits and brain pathologies in transgenic mice with Alzheimer's disease
}

Shao-wei Wang ${ }^{1 \dagger}$, Dong-qun Liu ${ }^{1 \dagger}$, Ling-xiao Zhang ${ }^{1 \dagger}$, Mei Ji ${ }^{1}$, Yang-xin Zhang ${ }^{1,2}$, Quan-xiu Dong ${ }^{1}$, Shu-ying Liu ${ }^{1,3}$, Xi-xiu Xie ${ }^{1}$ and Rui-tian Liu ${ }^{*}$

\begin{abstract}
Background: $\beta$-Amyloid peptide (A $\beta$ ) oligomers are initial factors used to induce Alzheimer's disease (AD) development, and $A \beta$ monomers have normal physiological function. The antibodies or vaccines against $A \beta$ monomers have serious problems, such as side effects and low curative effects. Therefore, it is essential to specifically target $A \beta$ oligomers rather than monomers for the treatment of AD.

Methods: The mimotopes of $A \beta$ oligomers were obtained by panning the phage-displayed random peptide libraries using oligomer-specific antibodies as targets and expressed on the surface of EBY100 Saccharomyces cerevisiae to generate yeast cell base vaccines. One vaccine (AOE1) induced antibodies specifically against Aß oligomers and was selected for further study. The APP/PS1 mice were subcutaneously immunized with AOE1 eight times. The levels and characteristics of antibodies induced by AOE1 were determined by enzyme-linked immunosorbent assay. The effect of AOE1 on the cognitive deficits of AD mice was tested by novel object recognition (NOR) and Y-maze. Dot blot analysis, Western blot analysis, and immunohistochemistry were applied to measure the effects of AOE1 on A $\beta$ pathologies, neuroinflammation, and microhemorrhages in the brains of AD mice.
\end{abstract}

Results: Eight mimotope candidates of A oligomers were selected and expressed on EBY 100 S. cerevisiae. Only $A O E 1$ vaccine containing mimotope $L 2$ induced antibodies that specifically recognized $A \beta 42$ oligomers rather than monomers. AOE1 immunization significantly increased the AD mice's exploration times for the novel object in the NOR test and the choices for new arms in the Y-maze test, and it reduced levels of A $\beta$ oligomers and glial activation in the AD mouse brains. No activation of $A \beta$-specific $T$ cells and microhemorrhages was observed in their brains following AOE1 vaccination.

Conclusions: AOE1 is the first vaccine applying the oligomer-specific mimotope as an immunogen, which could induce antibodies with high specificity to $A \beta$ oligomers. AOE1 immunization attenuated $A \beta$ pathologies and cognitive deficits in AD mice, decreased the overactivation of glial cells, and did not induce microhemorrhage in the brains of $A D$ mice. These findings suggest that AOE1 may be a safer and more effective vaccine for AD treatment.

Keywords: Alzheimer's disease, $\beta$-amyloid oligomer, Mimotope, Saccharomyces cerevisiae, Vaccine

\footnotetext{
* Correspondence: rtliu@ipe.ac.cn

${ }^{\dagger}$ Equal contributors

${ }^{1}$ National Key Laboratory of Biochemical Engineering, Institute of Process

Engineering, Chinese Academy of Sciences, Haidian District, Beijing 100190,

China

Full list of author information is available at the end of the article
} 


\section{Background}

Alzheimer's disease (AD) is the most prevalent dementia that seriously threatens the health and life of the elderly [1]. The hallmark pathologies of AD are neuronal extracellular senile plaques consisting of $\beta$-amyloid peptide (A $\beta)$ aggregates and intracellular neurofibrillary tangles consisting of abnormally hyperphosphorylated tau protein [2]. $A \beta$ oligomers, aggregated from $A \beta$ monomers, are considered to be the initial cause of $\mathrm{AD}$ by inducing tau hyperphosphorylation, oxidative stress, inflammatory response, synaptic dysfunction, and subsequent neurodegeneration that underlie the progression of $\operatorname{AD}[3,4]$. $\mathrm{A} \beta$ is a proteolytic fragment of the amyloid precursor protein (APP) by the sequential enzymatic actions of $\beta$ secretase and $\gamma$-secretase [5]. APP and A $\beta$ play trophic roles in the development of neurons and synapses $[6,7]$. $\mathrm{A} \beta$ may exist in several forms, including monomers, oligomers, and fibrils, whereas only the oligomeric forms were considered to be more neurotoxic [8].

Anti-A $\beta$ immunotherapy is an efficient way to clear the $A \beta$ burden and has promising applications in $A D$ treatment. However, the risk of autoimmunity and notable side effects, as well as uncertain therapeutic effects, have restricted the development of immunotherapy against $A \beta$ [9]. The first $A \beta$ vaccine, $A N 1792$ using $A \beta_{42}$ fibrils as an immunogen, significantly reduced the amyloid burden in AD transgenic mice after vaccination [10]. Unfortunately, AN1792 was terminated in clinical trials because of meningoencephalitis that occurred in $6 \%$ of immunized patients with AD [11]. Subsequent research indicated that $\mathrm{T}$-cell-mediated autoimmunity induced by the self-antigen $A \beta_{1-42}$ was the main cause of this serious adverse effect [12]. To avoid T-cell autoimmunity, the second generation of $A \beta$ vaccines was developed by conjugating a B-cell epitope of $A \beta_{42}$ with a carrier [13]. However, the antibodies elicited by these vaccines bound to A $\beta$ monomers, oligomers, fibrils, and even APP $[14,15]$, also leading to cerebral edema and microvascular hemorrhage in the brains of patients with $\mathrm{AD}$, and they did not show remarkably therapeutic effects in the clinical trials [16-18]. Passive immunotherapy using antibodies against $\mathrm{A} \beta$ monomers, such as bapineuzumab [19] and solanezumab [20], was also unsuccessful in AD clinical trials. However, aducanumab, an antibody recently developed by Biogen (Cambridge, MA, USA), selectively targeted aggregated $A \beta$, reduced $A \beta$ levels in brains, and inhibited the clinical decline of recognition in patients with prodromal or mild $\mathrm{AD}$ in a phase I clinical trial. Aducanumab entered phase III clinical trials directly without a phase II clinical study [4]. Another phase III clinical study demonstrated that intravenous immunoglobulin (IVIG) exhibited beneficial effects on the subgroup of moderate and apolipoprotein E $\varepsilon 4$ allele carrier patients with $\mathrm{AD}[21]$. The antibodies against $\mathrm{A} \beta$ oligomers in IVIG were considered to contribute to these beneficial effects on AD treatment [22]. Consistently, our $\mathrm{A} \beta$ oligomer-specific antibodies $(\mathrm{A} \beta \mathrm{O})$ purified from IVIG (IVIG-A $\beta \mathrm{O}$ ) attenuated the cognitive deficits and $\mathrm{A} \beta$ pathologies in APPswe/PS1dE9-transgenic mice [23]. These studies suggest that antibodies targeting A $\beta$ oligomers may exert more efficient therapeutic effects on $\mathrm{AD}$ treatment. To generate a vaccine that induces antibodies to specifically neutralize $A \beta$ oligomers, we first obtained $\mathrm{A} \beta_{42}$ oligomeric mimotopes by panning the phagedisplayed random peptide libraries using IVIG-A $\beta O$ as the target protein, then we expressed these mimotopes on EBY100 Saccharomyces cerevisiae to develop a novel A $\beta$ oligomer-specific vaccine.

\section{Methods \\ Materials}

The Ph.D. ${ }^{\mathrm{Tm}}$-12 Phage Display Peptide Library was obtained from New England Biolabs (Ipswich, MA, USA). A $\beta_{42}$ was purchased from the American Peptide Company (Sunnyvale, CA, USA). IVIG-A $\beta O$ were purified from IVIG by $A \beta_{42}$ oligomer affinity chromatography at our laboratory [23]. EBY100 S. cerevisiae was a generous gift from Dr. Xiang-mei Liu, Shandong University, Jinan, China. Both $A \beta_{40}$ and $A \beta_{42}$ kits for $A \beta$ measurement were purchased from Immuno-Biological Laboratories Co., Ltd. (Gunma, Japan). The following antibodies were used: 4G8 (monoclonal raised against $A \beta_{17-24}$; Signet Laboratories/ Covance Research Products, Denver, PA, USA), antiionized calcium-binding adaptor molecule-1 (anti-Iba-1) polyclonal antibody (GeneTex, Irvine, CA, USA), 9E10 (anti-c-Myc antibody; Santa Cruz Biotechnology, Dallas, TX, USA), anti-glial fibrillary acidic protein (anti-GFAP) monoclonal antibody (Cell Signaling Technology, Danvers, MA, USA), and anti-synaptophysin antibody (Abcam, Cambridge, UK). HRP-conjugated goat antimouse immunoglobulin G (IgG) antibody and HRPconjugated goat antirabbit IgG antibody were obtained from Beijing Zhongshan Golden Bridge Biotechnology Co., Ltd. (Beijing, China). IL-4 and interferon (IFN)- $\gamma$ enzyme-linked immunospot (ELISPOT) assay kits were purchased from Shenzhen DAKEWEI Co. Ltd. (Shenzhen, China). The iron stain kit we used was purchased from Sigma-Aldrich (St. Louis, MO, USA). The enhanced chemiluminescence (ECL) kit we used was purchased from Thermo Fisher Scientific (Waltham, MA, USA).

\section{Preparation of $A \beta$ monomers, oligomers, and fibrils}

$\mathrm{A} \beta_{42}$ (American Peptide Company) was dissolved in $100 \%$ hexafluoroisopropanol (HFIP) to a concentration of $1 \mathrm{mg} / \mathrm{ml}$, sonicated in a water bath for 5 minutes, aliquoted into microcentrifuge tubes, vacuum-dried, and stored at $-20{ }^{\circ} \mathrm{C}$. Immediately prior to use, the 
HFIP-treated $A \beta_{42}$ was dissolved in dimethyl sulfoxide (DMSO) to $2 \mathrm{mg} / \mathrm{ml}$ and diluted to $80 \mu \mathrm{M}$ in $20 \mathrm{mM}$ PBS buffer (monomer solution), pH 7.4, and then incubated at $37{ }^{\circ} \mathrm{C}$. The states of incubated $\mathrm{A} \beta$ were checked using transmission electron microscopy and thioflavin $\mathrm{T}$ dye at different time points, and $\mathrm{A} \beta$ after $2 \mathrm{~h}$ and $24 \mathrm{~h}$ incubation was used as an oligomer and a fibril, respectively.

\section{Screening and identification of oligomeric mimotopes}

The oligomeric mimotope peptides were obtained by screening peptide libraries through phage display as previously described [24]. The Ph.D. ${ }^{\mathrm{T}}-12$ Phage Display Peptide Library was applied, and the oligomer-specific antibody IVIG-A $\beta O$ was used as the target protein. After 4 rounds of selection, 44 positive clones were picked up and sequenced, and their sequences were analyzed by using the BLAST program for a homology search. Eight candidates were selected.

\section{Vaccine preparation}

To increase the immunogenicity of the mimotope peptides, a DNA fragment encoding the mimotope peptides was inserted into a modified vector of pCTCON2 and transfected into EBY100 (S. cerevisiae) as previously described $[25,26]$. The mimotope peptide was conjugated with a c-Myc tag in its $\mathrm{C}$-terminus and linked to the C-terminus of the AGA2 protein with a linker. The displayed mimotope on the yeast cells was determined by flow cytometry and confocal microscope after probing with anti-c-Myc antibody and fluorescein isothiocyanate (FITC)-labeled secondary antibody. The EBY100 displaying $A \beta_{15}$ was used as the positive control, and EBY100 yeast cells alone served as the negative control. All of the yeast cell-based vaccine was heatinactivated $\left(56{ }^{\circ} \mathrm{C}, 1 \mathrm{~h}\right)$ and stored at $-80{ }^{\circ} \mathrm{C}$ until use.

\section{Mouse immunization}

To screen the $A \beta$ oligomer-specific vaccines, C57BL/6 J mice (female, 6 weeks of age, $n=3$ for each group) were immunized with $6 \times 10^{7}$ cells of yeast-based vaccines twice at biweekly intervals. To evaluate the therapeutic effects of the vaccine, APP/PS1 double-transgenic mice with a C57BL/6 J background were purchased from The Jackson Laboratory (Bar Harbor, ME, USA). The transgenic mice and their littermate wild-type (WT) control mice (males, 6 months of age) were maintained with access to food and water ad libitum in a colony room kept at $22 \pm 2{ }^{\circ} \mathrm{C}$ and $50 \pm 5 \%$ humidity under a $12-\mathrm{h} / 12-\mathrm{h}$ light/dark cycle.

APP/PS1 mice (males, 6 months of age) were immunized with $6 \times 10^{7}$ cells of EBY100 $(n=10)$, AOE1 $(n=10)$, and $\mathrm{A} \beta_{15}(n=5)$ eight times at biweekly intervals. WT mice were immunized with PBS. Blood samples were taken at regular intervals, and sera were prepared and stored at $-80{ }^{\circ} \mathrm{C}$ until further use. All experimental protocols were approved (reference number 15-LRT1) by the Tsinghua University Animal Care and Use Committee. Experiments were performed according to the U.S. Animal Welfare Act and the Public Health Service Policy on Humane Care and Use of Laboratory Animals of the National Institutes of Health.

\section{Antibody titer determination}

An indirect enzyme-linked immunosorbent assay (ELISA) was used to measure the titers of vaccine-induced antibodies in sera against $A \beta_{42}$ oligomers and mimotope peptides. Ninety-six-well ELISA plates were coated with $\mathrm{A} \beta_{42}$ oligomers (500 ng/well) or mimotope peptides $(1 \mu \mathrm{g} /$ well $)$ overnight at $4{ }^{\circ} \mathrm{C}$. After the plates were blocked with 3\% (wt/vol) bovine serum albumin in PBS for $2 \mathrm{~h}$ at $37^{\circ} \mathrm{C}$, twofold serial dilutions of sera were added in triplicates and incubated for $2 \mathrm{~h}$ at $37{ }^{\circ} \mathrm{C}$. The bound antibodies were detected by adding HRP-conjugated antimouse antibody and 3,3',5,5' -tetramethylbenzidine substrate. The enzyme reaction was stopped by adding $2 \mathrm{M}$ $\mathrm{H}_{2} \mathrm{SO}_{4}$, and the optical density (OD) at $450 \mathrm{~nm}$ was recorded by using a SpectraMax M5 microplate reader (Molecular Devices, Sunnyvale, CA, USA).

The levels of different IgG subclasses were also assayed by indirect ELISA. After incubation of sera (dilution to 1:100), HRP-conjugated antimouse IgG1, IgG2a, IgG2b, and IgG3 antibodies (Santa Cruz Biotechnology) were added to the plates in a 1:5000 dilution and incubated at $37^{\circ} \mathrm{C}$ for $1 \mathrm{~h}$. Then the OD values were detected as described above.

\section{Behavioral tests}

Novel object recognition (NOR) and a Y-maze were applied to detect cognitive function in immunized mice as previously described [27]. The NOR test is based on the spontaneous tendency of mice to exhibit more interactions with a novel rather than a familiar object. In the habituation phase, each mouse was allowed to freely explore the open-field area (a white box $40 \mathrm{~cm}$ wide $\times$ $40 \mathrm{~cm}$ deep $\times 40 \mathrm{~cm}$ high) in the absence of objects. During the familiarization period, each mouse was placed in the box, which contained two identical objects, for 5 minutes. Recognition memory was tested after $24 \mathrm{~h}$ by exposing the mice to one familiar and one novel object. The time spent exploring and sniffing each object was recorded. The discrimination index was determined by performing the following calculation: $\left(\right.$ Time $_{\text {novel }}-$ Time $\left._{\text {old }}\right) /\left(\right.$ Time $_{\text {novel }}+$ Time $\left._{\text {old }}\right)$.

After the NOR tests, the spatial recognition memory of the mice was tested by using the Y-maze test. Y-mazes were made of gray wood, covered with black paper, and consisted of three arms with an angle of 120 degrees 
between each arm. Each arm was $8 \mathrm{~cm} \times 30 \mathrm{~cm} \times 15 \mathrm{~cm}$ (width $\times$ length $\times$ height). The three identical arms were randomly designated as the start arm, in which the mouse started to explore (always open); the novel arm, which was blocked during the first trial but open during the second trial; and the other arm (always open). The Y-maze test consisted of two trials separated by an intertrial interval (ITI) to assess spatial recognition memory. The first trial (training) had a 10-minute duration and allowed the mouse to explore only two arms (start arm and other arm) of the maze, with the third arm (novel arm) being blocked. After a 1-h ITI, all three arms were accessible for the mice for the second trial. The mice were placed back in the maze in the starting arm, with free access to all three arms for 5 minutes. By using a ceiling-mounted charge-coupled device camera, all trials were recorded on a videocassette recorder, and the number of entries and time spent in each arm in the video recordings were analyzed.

\section{Dot blot analysis}

Dot blot analysis was used to test the binding of vaccine-induced antibodies to various $A \beta_{42}$ aggregates. Briefly, samples of $A \beta_{42}$ monomers, oligomers, and fibrils were applied to the membranes and blocked at room temperature (RT) for $1 \mathrm{~h}$ with $5 \%$ nonfat milk. The membranes were then incubated at RT for $1 \mathrm{~h}$ with mouse sera diluted in PBS with Tween-20 (PBST), washed thrice for 10 minutes each, and incubated with relevant secondary antibodies in PBST for $1 \mathrm{~h}$. The blots were washed thrice and developed with an ECL kit (Pierce Biotechnology, Rockford, IL, USA).

\section{Western blot analysis}

7PA2 cell (CHO cells stably transfected with a complementary DNA-encoding APP751 that contains the Val717Phe familial AD mutation) lysates were used to determine the binding capacity of vaccine-induced antibodies to various $A \beta$ aggregates. The cell extracts mixed with $A \beta$ monomers were boiled together with $5 \times$ loading buffer in the presence of dithiothreitol (DTT) for $10 \mathrm{mi}-$ nutes and electrophoresed on a 4-12\% SDS-PAGE gel, and then the gel was transferred onto a nitrocellulose (NC) membrane. The membrane was probed with 4G8 and vaccine-induced antibodies, followed by HRPconjugated antimouse IgG, and then developed with an ECL kit.

To determine the change of $A B$ oligomers in the $A D$ mouse brains after vaccination, brain extracts were boiled together with $5 \times$ loading buffer in the presence of DTT for 10 minutes and loaded onto a $4-12 \%$ SDSPAGE gel. The separated proteins were transferred onto $\mathrm{NC}$ membranes, which were then washed and incubated with 4G8 overnight at $4{ }^{\circ} \mathrm{C}$. The membranes were washed again and incubated with HRP-conjugated secondary antibody for $1 \mathrm{~h}$ at RT. The blots were developed with an ECL kit according to the manufacturer's instructions. The intensity of protein bands was quantified using ImageJ software (National Institutes of Health, Bethesda, MD, USA).

\section{Cerebral homogenate collection}

After the behavioral tests, the mice were immediately intraperitoneally anesthetized with avertin $(300 \mathrm{mg} / \mathrm{kg})$, perfused with ice-cold PBS containing heparin $(10 \mathrm{U} / \mathrm{ml})$, and then killed. The brain was rapidly removed and divided. One hemisphere was rapidly dissected and homogenized. The brain tissues were Dounce-homogenized in radioimmunoprecipitation assay (RIPA) buffer containing a protease inhibitor mixture, which consisted of $50 \mathrm{mM}$ Tris (pH 7.4), $150 \mathrm{mM} \mathrm{NaCl}, 1 \%$ Triton X-100, 1\% sodium deoxycholate, and $0.1 \%$ SDS. The tissues were then centrifuged at $14,000 \times g$ for 30 minutes at $4{ }^{\circ} \mathrm{C}$, and the supernatant (RIPA-soluble fraction) containing soluble $A \beta$ was collected. The pellets were resuspended in guanidine buffer $(5.0 \mathrm{M}$ guanidine- $\mathrm{HCl} / 50 \mathrm{mM}$ Tris- $\mathrm{HCl}, \mathrm{pH} 8.0)$ and centrifuged at $14,000 \times g$ for $1 \mathrm{~h}$ at $4{ }^{\circ} \mathrm{C}$ to obtain supernatants containing insoluble $A \beta$ (guanidine-soluble $A \beta$ ).

\section{Measurement of $A \beta_{40 / 42}$}

To determine the levels of $A \beta$ in the brain, RIPA-soluble and RIPA-insoluble (guanidine-soluble) $A \beta$ fractions of mice were quantified by ELISA using $A \beta_{40}$ and $A \beta_{42}$ immunoassay kits according to the manufacturer's instructions. The levels of soluble and insoluble $A \beta$ were standardized to the brain tissue weight and expressed in micrograms of $A \beta$ per gram of brain tissue.

\section{Immunohistochemistry}

Immunohistochemical staining was performed as previously described [28]. Briefly, 20- $\mu \mathrm{m}$-thick sections at intervals of $100 \mu \mathrm{m}$ were obtained using a freezing microtome (Leica Microsystems, Wetzlar, Germany) and mounted on poly-L-lysine-coated slides. The sections were washed in PBS and then treated briefly with $80 \%$ (vol/vol) methanol containing $0.3 \% \mathrm{H}_{2} \mathrm{O}_{2}$ to prevent endogenous peroxidation. The sections were then blocked with $10 \%$ normal goat serum to prevent nonspecific protein binding. Subsequently, the sections were incubated with the primary antibodies 6E10 (1:100), GFAP (1:100), Iba-1 (1:100), and synaptophysin (1:100) for $1 \mathrm{~h}$ at RT, followed by incubation with an HRP-labeled or fluorescence-labeled secondary antibody at RT for $1 \mathrm{~h}$. The targets were visualized with 3,3'-diaminobenzidine substrate and counterstained with hematoxylin. Images were collected using an Olympus BX60 microscope (Olympus Optical Co. Ltd., Tokyo, Japan) by using $\times 4$ and $\times 10$ 
lens objectives. IpWin5 analytical software was used to quantify the glial cells.

\section{Analysis of microhemorrhage}

To assess the number of microhemorrhages, sections were stained using the iron stain kit (Sigma-Aldrich) according to the manufacturer's protocol. Three slides per animal were analyzed. Prussian blue-positive spots in subregions of the cortex as well as in the hippocampus were manually counted.

\section{ELISPOT assay}

One week after the behavioral tests, three mice of each group were killed, and their splenocytes were isolated and analyzed for the presence of target-specific $T$ cells by ELISPOT analysis according to the manufacturer's protocol. Full-length $A \beta_{1-42}(10 \mathrm{mg} / \mathrm{ml})$, L2 peptides

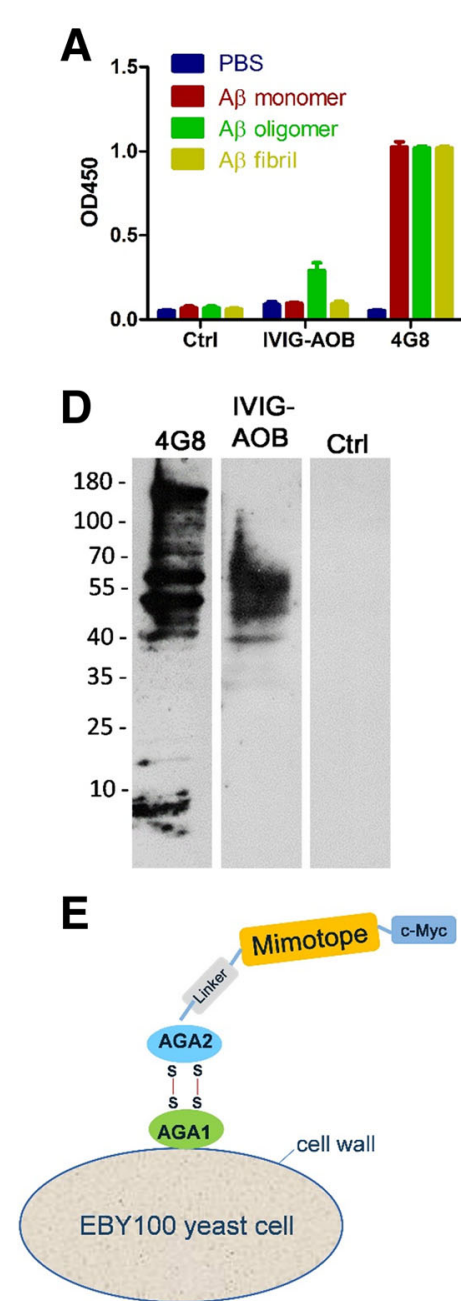

B

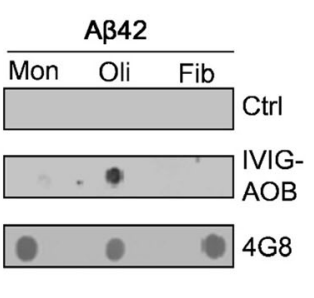

F
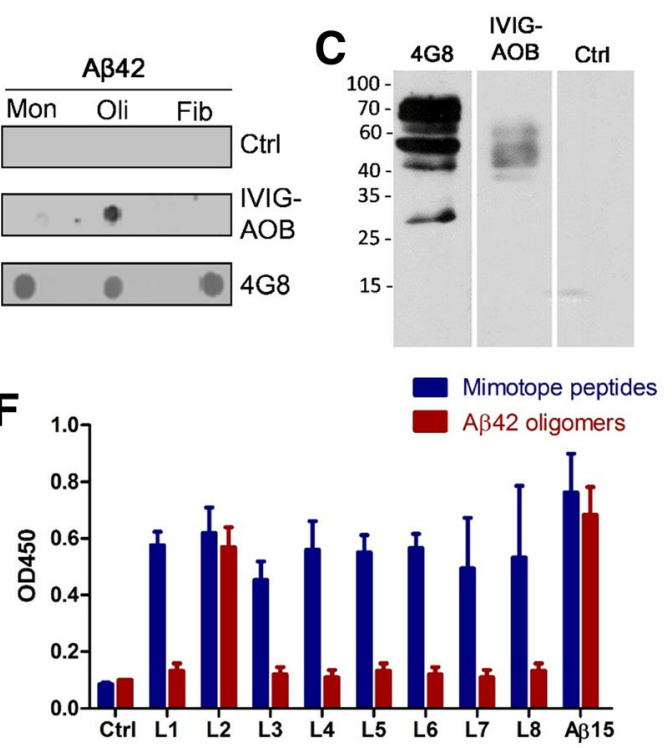

G

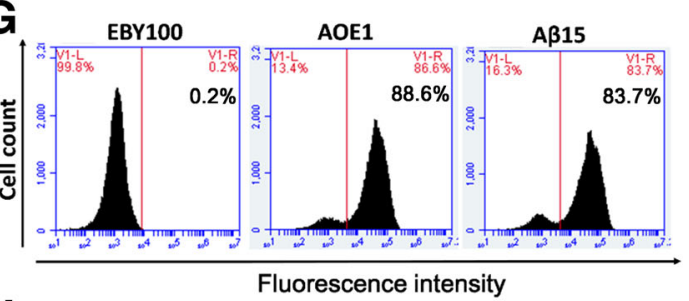

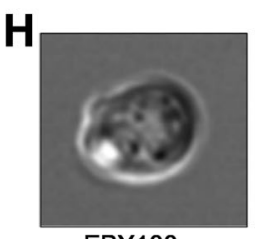

EBY100

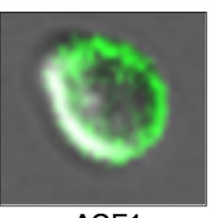

AOE1

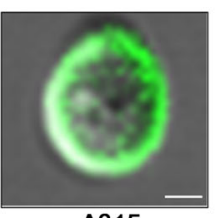

$\mathrm{A} \beta 15$

Fig. 1 Selection and expression of $\beta$-amyloid peptide $(A \beta)$ oligomer-specific mimotopes. a-d A $\beta$ oligomer-specific antibodies purified from intravenous immunoglobulin G (IVIG-ABO) specifically recognized A oligomers. The binding of IVIG-A $\beta O$ to different A $\beta$ forms was detected by enzyme-linked immunosorbent assay (ELISA) (a) and dot blot analysis (b), respectively. The brain homogenate of APP/PS1 mice (c) and 7PA2 cell lysates mixed with AB monomer (d) were separated on SDS-PAGE gels, and then Western blot analysis was performed with IVIG-AßO as primary antibodies. An irrelevant human monoclonal antibody and 4G8 were used as negative and positive controls, respectively. e Structural diagram of yeast-based vaccine. The mimotopes with c-Myc were linked with the C-terminal of AGA2 protein and displayed on the surface by interaction with AGA1. f C57BL/6 mice (female, 6 weeks of age, $n=3$ for each group) were subcutaneously injected twice at a 2-week interval with eight candidate yeast-based vaccines in the absence of adjuvant. The antibody titers against mimotope peptides and $A \beta_{42}$ oligomers in the mice immunized with different vaccines were detected by ELISA. One vaccine, EBY100-L2, was termed AOE1. g The AOE1 and A $\beta_{1-15}$ were expressed and displayed on the surface the EBY100 yeast cells. The cells were probed with anti-Myc antibody and fluorescein isothiocyanate-labeled secondary antibody and then analyzed by flow cytometry. EBY100 yeast cells were used as a negative control. $\mathbf{h}$ Expression of AOE1 and A $\beta_{1-15}$ was determined by confocal microscopy. The obvious fluorescent signals were detected on the surface of EBY100 yeast cells expressing $L 2$ and $A \beta_{1-15}$. Bar indicates $1 \mu \mathrm{m}$. OD450 Optical density at $450 \mathrm{~nm}$ 
$(10 \mathrm{mg} / \mathrm{ml})$, EBY100 $\left(10^{5}\right.$ cells $\left./ \mathrm{ml}\right)$, negative control DMSO and PBS, and positive control phorbol 12-myristate 13-acetate (PMA) and ionomycin were used for splenocyte restimulation. The levels of interleukin 4 (IL-4) or IFN- $\gamma$ were measured to evaluate T-cell stimulation.

\section{Statistical analysis}

Data were obtained from at least three independent experiments for each condition and are expressed as the mean \pm SEM. Statistical significance was analyzed using Student's $t$ test.

\section{Results}

\section{Selection and expression of $A \beta$ oligomer-specific} mimotopes

To construct a vaccine specifically against $A \beta$ oligomers, we first isolated $A \beta$ oligomeric mimotopes by screening the Ph.D. ${ }^{\mathrm{Tm}}-12$ Phage Display Peptide Library using IVIG$\mathrm{A} \beta \mathrm{O}$. The binding characteristics of the purified IVIG$\mathrm{A} \beta \mathrm{O}$ were detected by ELISA, dot blot analysis, and Western blot analysis. The results indicated that IVIG$A \beta O$ specifically recognized $A \beta$ oligomers rather than $A \beta$ monomers of fibrils (Fig. 1a-d). After four rounds of selection, positive clones were picked up and sequenced, and their sequences were analyzed by using the BLAST program for a homology search. Eight candidate epitope peptides (Table 1) were expressed and displayed on EBY100 S. cerevisiae (Fig. 1e) to generate whole-cell-based vaccines. EBY100 displaying the $A \beta_{1-}$ ${ }_{15}$ fragment was used as a vaccine control. To test the ability to elicit antibodies against $A \beta_{42}$ oligomers, nine yeast-based vaccines were subcutaneously injected into C57BL/6 mice two times. One vaccine, EBY100-L2 (termed $A O E 1$ ), could elicit anti-A $\beta_{42}$ oligomeric antibodies, whereas other vaccines induced antibodies only against mimotope peptides rather than $A \beta_{42}$ oligomers (Fig. 1f).

To further validate the exhibition of mimotope peptide L2 on the EBY100 surface, the yeast cells were incubated with anti-Myc antibody and then reacted with secondary

Table 1 Sequences of eight candidate mimotopes

\begin{tabular}{ll}
\hline Mimotope & Sequence \\
\hline L1 & RTTELEPYENEQ \\
L2 & RPDQVMWDSKRP \\
L3 & FLRMDHSALGSV \\
L4 & TRSWLRTQWWIR \\
L5 & TPSIGPNSTWLD \\
L6 & SWWSYWHSSHRH \\
L7 & HFYQAQKTTWAS \\
L8 & NFSGEHSSRNRP \\
\hline
\end{tabular}

antibody labeled with FITC for detection by flow cytometry and confocal microscopy. The yeasts expressing L2 and $A \beta_{1-15}$ showed obvious signals in comparison to EBY100 yeast cell controls (Fig. 1g). More than $80 \%$ of the yeast cells were signal-positive in both groups expressing L2 or $A \beta_{1-15}$. Moreover, the confocal microscopy results also indicated that $\mathrm{L} 2$ and $A \beta_{1-15}$ peptides were displayed on the surface of the yeast (Fig. 1h), whereas no green fluorescence was detected on the EBY100 yeast cell controls.

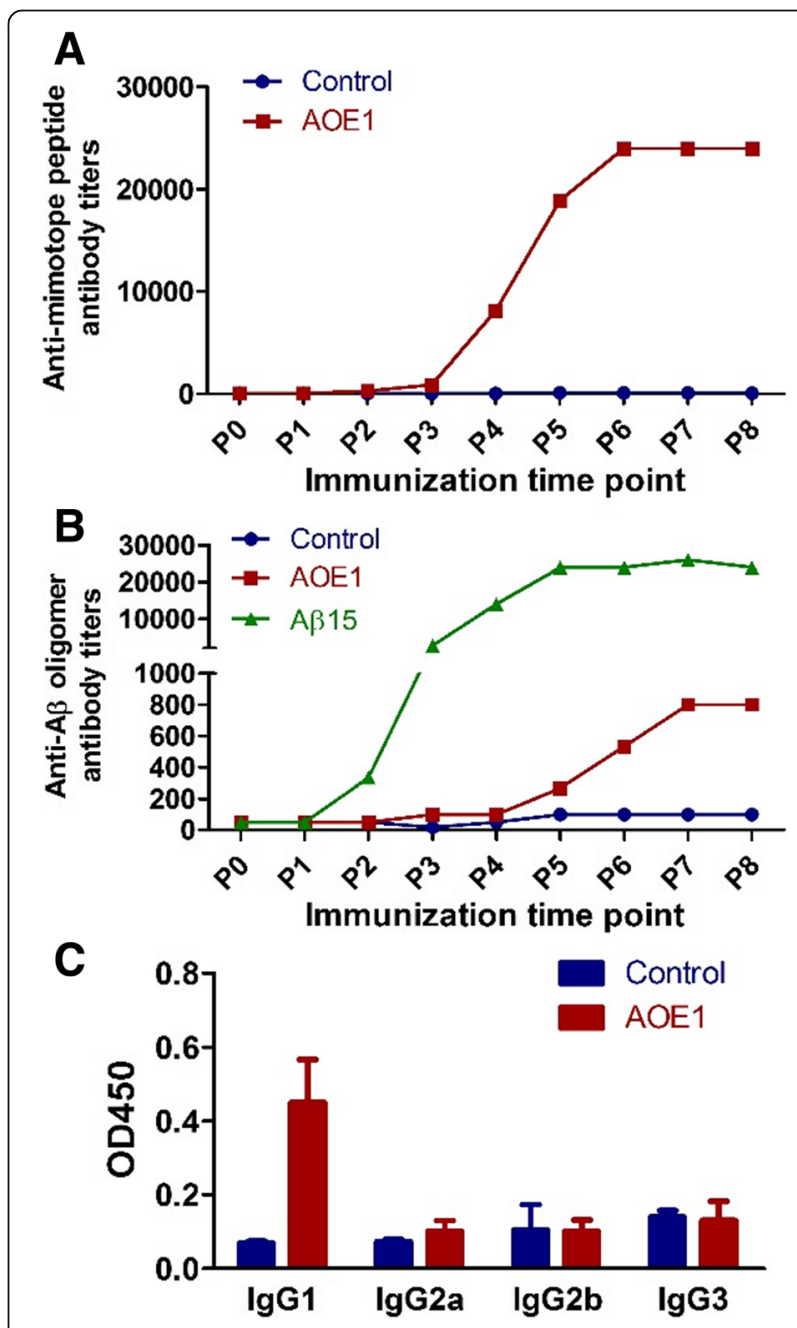

Fig. 2 The titer and subtype of antibody in Alzheimer's disease (AD) transgenic mice immunized with EBY100-L2 vaccine (AOE1). APP/PS1 mice (male, 6 months of age) were subcutaneously injected eight times at 2-week intervals with $A O E 1, A \beta_{15}$, and EBY100 control cells in the absence of adjuvant. The titers and subtypes of antibody in the mouse sera were detected by enzyme-linked immunosorbent assay. $\mathbf{a}$ The titers of antibody against mimotope peptide $L 2$ in the mice immunized with AOE1 vaccine. $\mathbf{b}$ The titers of antibody against $A \beta_{42}$ oligomers in the mice immunized with AOE1 vaccine. c Subtype of immunoglobulin $\mathrm{G}$ against $A \beta_{42}$ oligomers. OD450 Optical density at $450 \mathrm{~nm}$ 


\section{Immunogenicity of AOE1}

To test the immunogenicity of AOE1, APP/PS1 mice were injected subcutaneously eight times at 2-week intervals with a dose of $6 \times 10^{7}$ cells in the absence of adjuvant. EBY100 yeast cells were used as negative controls. The antibody titers were measured with synthetic mimotope peptides and $\mathrm{A} \beta$ oligomers as the antigens, respectively. After the sixth immunization, AOE1 induced a high antibody titer against mimotope peptide to 1:24,000, whereas no antibody was detected in the control group (Fig. 2a). Moreover, the antibody induced by $A O E 1$ recognized $A \beta$ oligomers, and its titer reached 1:800 (Fig. 2b). To determine the isotypes of the anti-A $\beta$ oligomer IgG induced by AOE1, sera from the mice were diluted (1:100) and tested by indirect ELISA. The results indicated that IgG1 was the predominant form of the antibody, whereas IgG2a, IgG2b, and IgG3 were detected at low levels, suggesting that AOE1 induced a noninflammatory type 2 helper T-cell immune response (Fig. 2c).

\section{Specificity of the antibody induced by AOE1}

To further determine the specificity of the antibody induced by AOE1, A $\beta$ monomers, oligomers, and fibrils were coated onto ELISA plates and incubated with the sera of mice vaccinated with AOE1. The results indicated that the antibody induced by $A \beta_{1-15}$ vaccine, just like the anti-A $\beta$ monomer antibody $4 \mathrm{G} 8$, bound to all forms of $A \beta$, whereas the AOE1-elicited antibodies specifically bound to $A \beta$ oligomers rather than to $A \beta$ monomers, and also bound $A \beta$ fibrils with low affinity (Fig. 3a). Consistent with our ELISA results, our dot blot analysis results also showed that AOE1-induced sera strongly bound to $A \beta$ oligomers but not to monomers, although $A \beta_{1-15}$-induced sera and 4G8 recognized all forms of $A \beta$ (Fig. 3b). These results indicated that AOE1 vaccine stimulated mainly the production of oligomer-specific antibodies.

To confirm the size of $A \beta$ oligomers to which AOE1 induced sera bound, Western blot analysis was performed using 7PA2 cell lysates mixed with $A \beta_{42}$ monomers or brain homogenates of APP/PS1 mice as antigens. $\mathrm{A} \beta_{15}$-stimulated sera and $4 \mathrm{G} 8$ antibody bound to all sizes of $A \beta$, whereas sera induced by AOE1 bound to $A \beta$ oligomers from a range of $35-100 \mathrm{kDa}$ (Fig. 3c, d), which was consistent with the binding of IVIG-A $\beta O$ to $\mathrm{A} \beta$.

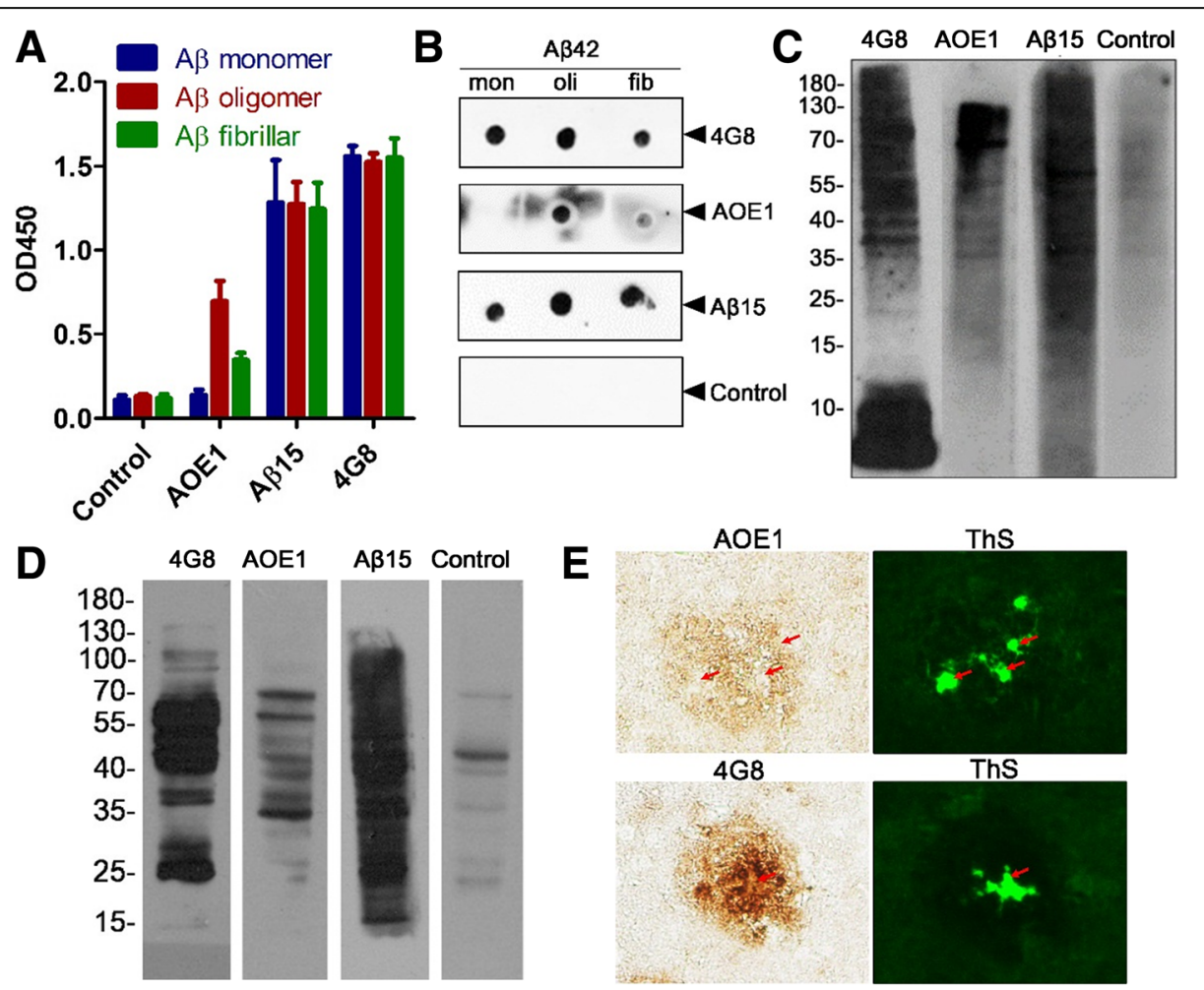

Fig. 3 The antibody induced by EBY100-L2 vaccine (AOE1) specifically recognized $\beta$-amyloid peptide (A $\beta$ ) oligomers. After the last immunization, the sera from the mice immunized with $A O E 1$ vaccine or $A \beta_{15}$ were diluted to 1:100 or 1:1000, respectively. The binding of antibodies induced by $A O E 1$ vaccine or $A \beta_{15}$ to different $A \beta$ isoforms was detected by enzyme-linked immunosorbent assay (a) or dot blot analysis (b), respectively. 7PA2 cell lysates mixed with A $\beta$ monomer (c) and brain homogenate of APP/PS1 mice (d) were separated on SDS-PAGE gels, and then Western blot analysis was performed with sera from vaccine-immunized mice as primary antibodies. e Brain sections from APP/PS1 mice were incubated with sera of AOE1-treated mice and 4G8 and then stained with thioflavin S (ThS). Red arrows indicate the ThS-positive compact plaques. OD450 Optical density at $450 \mathrm{~nm}$ 
To determine whether the AOE1-induced antibody bound to endogenous $A \beta$ plaques, the brain sections of APP/PS1 mice were stained by performing immunohistochemistry (IHC) using AOE1-induced sera with 4G8 as a positive control. The results showed that 4G8 strongly bound to both the diffuse and compact regions of plaques, but AOE1-induced sera selectively bound to loose rather than compact regions, which were remarkably stained by thioflavin $\mathrm{S}$ (ThS) (Fig. 3e), consistent with previous reports that the dense cores of plaques are composed mainly of $A \beta$ fibrils and few oligomers [29]. These results further confirmed that AOE1-induced sera recognized mainly $A \beta$ oligomers.

\section{AOE1 vaccination attenuates cognitive impairment in APP/PS1 mice}

NOR and Y-maze tests were conducted to evaluate the effect of AOE1 vaccination on cognitive function in APP/PS1 transgenic mice. During the probe trial of the NOR test, the exploration times for the novel object among AOE1-treated mice were significantly increased compared with the old object, whereas the controltreated mice exhibited similar exploration times for recognizing both novel and old objects ( $t$ test, $p=0.005, n$ $=10$ ) (Fig. 4a). The discrimination index of AOE1treated mice showed a marked increase compared with that of the control-treated mice ( $t$ test, $p=0.008, n=10$ ) (Fig. 4b). In the Y-maze test, AOE1-treated mice spent more time in the new arm and entered into the new arm more times than the control-treated mice ( $t$ test; for time in new arm, $p=0.04, n=10$; for choice of new arm, $p=0.03, n=10$ ) (Fig. 4c, d). Taken together, these results indicated that AOE1 vaccine treatment attenuated cognitive impairment in AD transgenic mice.

\section{$A O E 1$ vaccination lowers cerebral $A \beta$ levels in $A D$ transgenic mice}

To investigate the effects of $A O E 1$ vaccine on the $A \beta$ burden in the brains of AD transgenic mice, we detected A $\beta$ deposits by ThS staining and IHC using 4G8 antibody. No A $\beta$ deposits were detected in the brain tissues of WT mice. The AD mouse controls formed robust senile plaques in the cortex and hippocampus, whereas the plaque numbers in brain sections of AOE1- or $\mathrm{A} \beta_{15^{-}}$ treated mice decreased ( $t$ test; ThS staining, $p<0.05$ for AOE1, $p<0.01$ for $\mathrm{A} \beta_{15}, n=7$; $4 \mathrm{G} 8 \mathrm{IHC}, p<0.01$ for cortex and $p<0.05$ for hippocampus of AOE1 and $A \beta_{15}$, $n=7$ ) (Fig. 5).

Further, we detected the levels of soluble and insoluble $\mathrm{A} \beta$ in the mouse brains by ELISA. Compared with levels in $\mathrm{AD}$ control mice, the levels of soluble and insoluble $\mathrm{A} \beta_{40}$ and soluble $\mathrm{A} \beta_{42}$ in $\mathrm{AOE} 1$ - or $\mathrm{A} \beta_{15}$-treated AD mice significantly decreased ( $t$ test; soluble $\mathrm{A} \beta_{40}, p<0.05$ for AOE1, $p<0.01$ for $\mathrm{A} \beta_{15}, n=7$; insoluble $\mathrm{A} \beta_{40}, p=0.048$
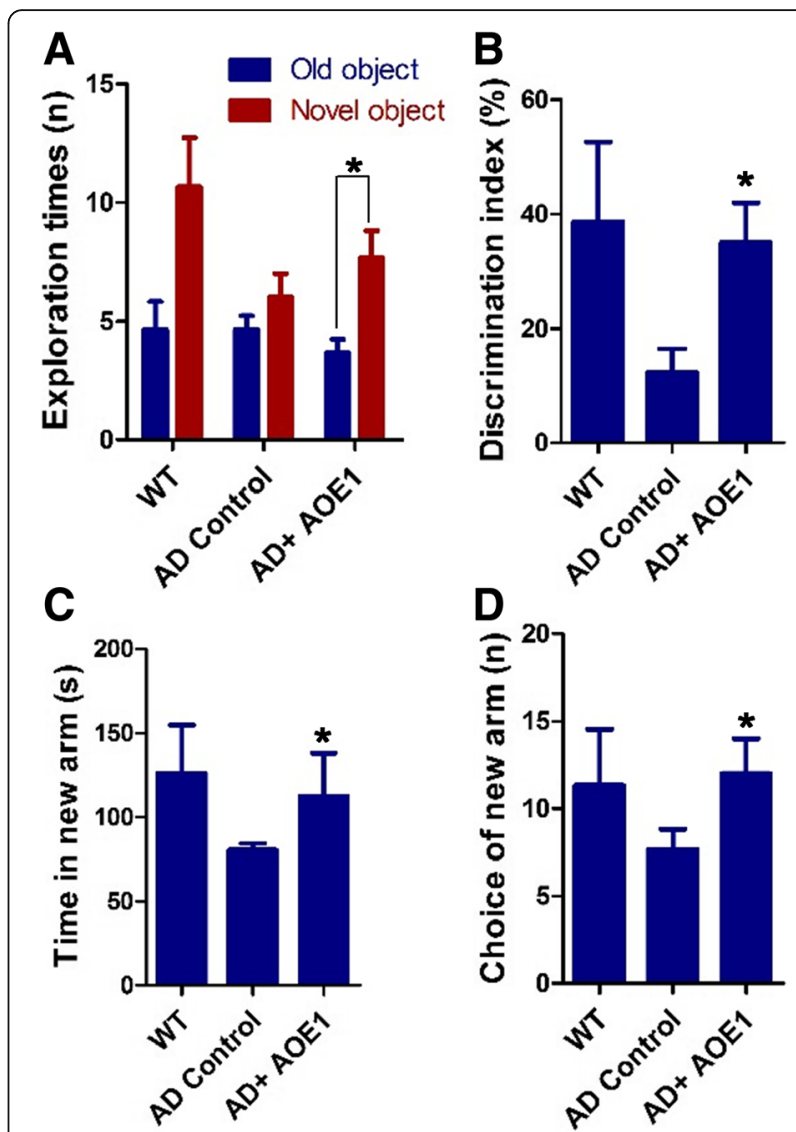

Fig. 4 EBY100-L2 (AOE1) vaccination attenuated cognitive deficits in APP/PS1 transgenic mice. The cognitive function of Alzheimer's disease (AD) mice was determined by novel object recognition (NOR) and Y-maze tests 2 weeks after the last vaccination. a Exploration times of mice for the old and new objects during NOR tests (compared with exploration times for old object, ${ }^{*} p<0.05$ ). b Discrimination index of mice for the new object during the NOR test (compared with AD control, $\left.{ }^{*} p<0.05\right)$. $\mathbf{c}$ and $\mathbf{d}$ Time spent in the new arm (c) and the entries into the new arm (d) of mice vaccinated with or without AOE1 vaccine (compared with AD control, ${ }^{*} p<0.05$ ). WT Wild type

for $\mathrm{AOE} 1, p=0.003$ for $\mathrm{A} \beta 15, n=7$; soluble $\mathrm{A} \beta_{42}, p=0.03$ for $\mathrm{AOE} 1, p=0.004$ for $\mathrm{A} \beta 15, n=7$ ) (Fig. $6 \mathrm{a}-\mathrm{C}$ ). AOE1 immunization also decreased the insoluble $A \beta_{42}$ level, but without statistical significance ( $t$ test, $p=0.10, n=7$ ) (Fig. 6d), whereas $A \beta_{15}$ significantly reduced the insoluble $\mathrm{A} \beta_{42}$ level ( $t$ test, $p<0.01, n=7$ ) (Fig. $6 \mathrm{~d}$ ).

Soluble $A \beta$ oligomer levels are related to cognitive decline in patients with $\mathrm{AD}$ [30]. To test whether $A O E 1$ vaccination reduced the levels of $A \beta$ oligomers, the mouse brain extracts were explored by Western blot analysis. AOE1 or $A \beta_{15}$ immunization significantly decreased the levels of $A \beta$ oligomers with a molecular weight range from 40 to $60 \mathrm{kDa}(t$ test, $p=0.046$ for $\mathrm{AOE} 1, p=0.014$ for $\mathrm{A} \beta 15, n=3$ ) (Fig. 6e, f), whereas the levels of oligomers with a molecular weight around $70 \mathrm{kDa}$ did not change (Fig. 6e, f). 

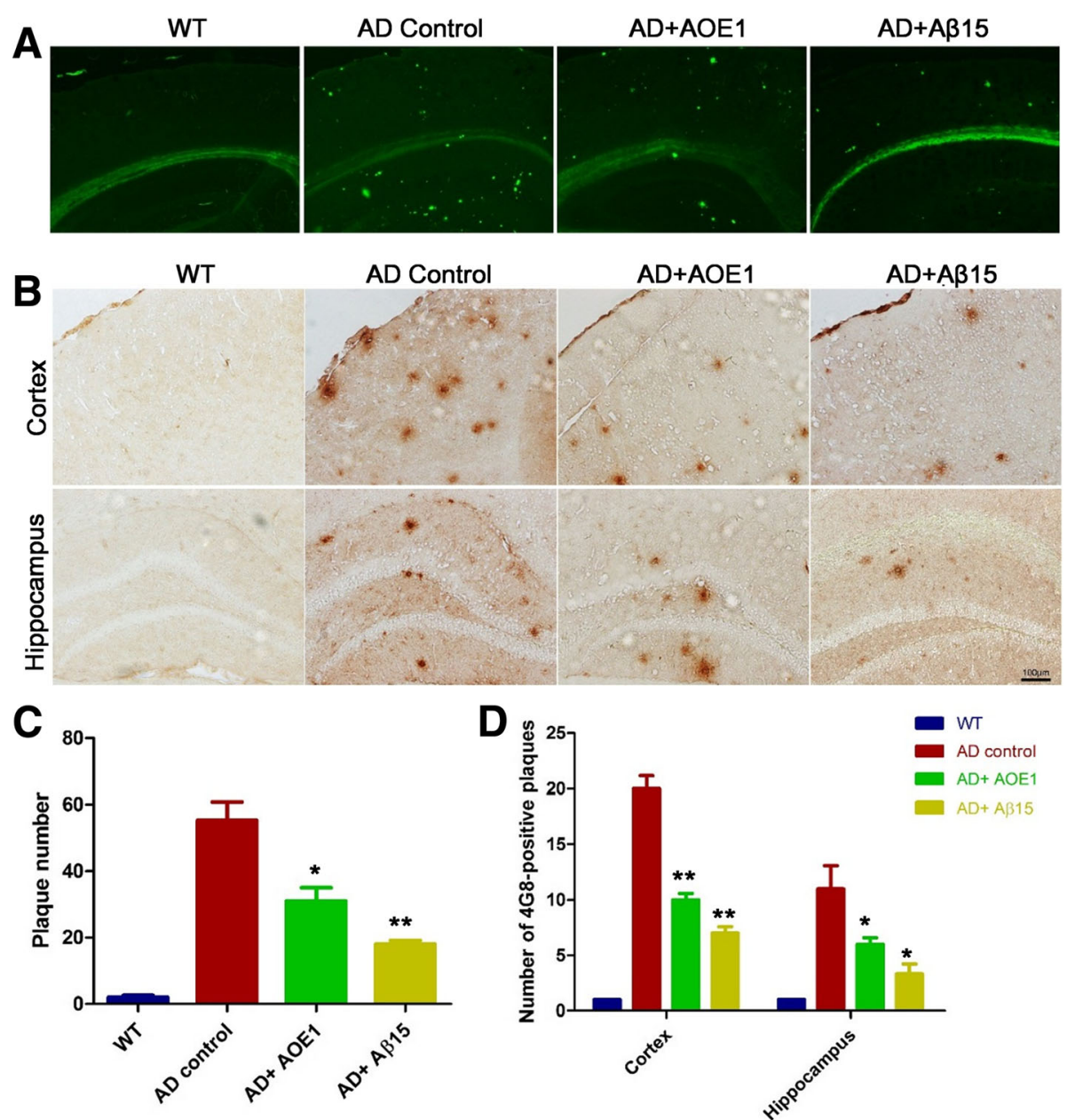

Fig. 5 EBY100-L2 (AOE1) immunization decreased $\beta$-amyloid peptide (A $\beta$ ) deposits in the brains of Alzheimer's disease (AD) mice. The plaques in the mouse brains were detected by thioflavin S (ThS) staining (a) and immunohistochemistry (IHC) using 4G8 (b), and the number of plaques in the brain sections stained by ThS staining (c) and $\mathrm{HC}(\mathbf{d})$ was quantified using IpWin5 software (compared with $A D$ control, * $\left.p<0.05,{ }^{* *} p<0.01\right)$. WT Wild type

\section{AOE1 vaccination suppresses activation of glia in brains of $A D$ mice}

Because neuroinflammation plays a major role in the pathogenesis of $\mathrm{AD}$, we next examined the effect of AOE1 treatment on the activation of astrocytes and microglia in the brains of mice with AD. To detected astrocyte activation, the brain slices were incubated with GFAP antibody and then probed with fluorescencelabeled secondary antibodies. In comparison with WT mice, a higher number of GFAP-immunopositive astrocytes were observed in the hippocampus and cortex of mice with $\mathrm{AD}$, but the number significantly decreased after AOE1 or $\mathrm{A} \beta_{15}$ treatment ( $t$ test; cortex, $p=0.02$ for AOE1, $p=0.02$ for $\mathrm{A} \beta_{15}, n=7$; hippocampus, $p<0.001$ for AOE1, $p<0.001$ for $\mathrm{A} \beta 15, n=7$ ) (Fig. 7a and c). Anti-Iba-1 antibody was used to determine the activation of microglia. The results showed that the number of activated microglia in the cortex of AD mice was sharply decreased after AOE1 vaccination ( $t$ test; cortex, $p<0.01$ for AOE1, $p<0.01$ for $\mathrm{A} \beta_{15}, n=7$; hippocampus, $p=0.16$ for AOE1, $p=0.53$ for $\mathrm{A} \beta_{15}, n=7$ ) (Fig. $7 \mathrm{~b}$ and d). These results indicated that AOE1 treatment suppressed the activation of astrocytes and microglia in vivo.

\section{AOE1 vaccination does not activate $A \beta$-specific $T$ cells and trigger microhemorrhages}

Previous reports demonstrated that $A \beta$ vaccination might induce a T-cell-dependent immune response, resulting in meningoencephalitis and cephaledema. To explore the effect of AOE1 vaccination on the activation of $A \beta$-specific T cells, we measured the levels of IFN- $\gamma$ and IL- 4 by ELISPOT assay using the splenocytes of AD mice immunized with or without AOE1. The cultured splenocytes were stimulated with EBY100 yeast cells, $A \beta_{42}$ peptide, and L2 peptide, respectively, with DMSO and PBS used as the negative controls and PMA/ionomycin [31] used as the 

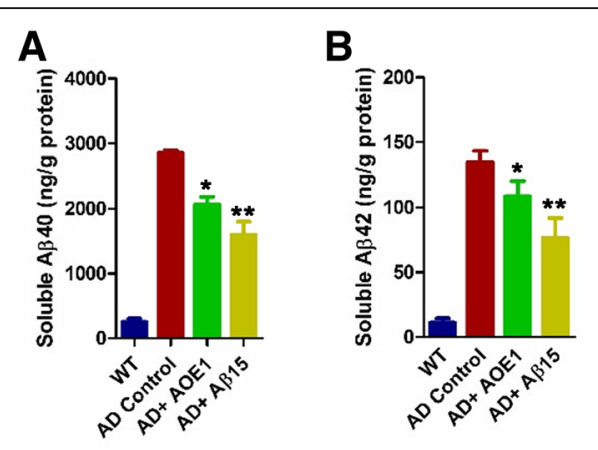

\section{E}

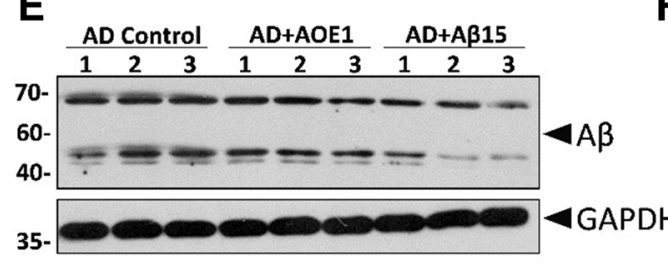

C
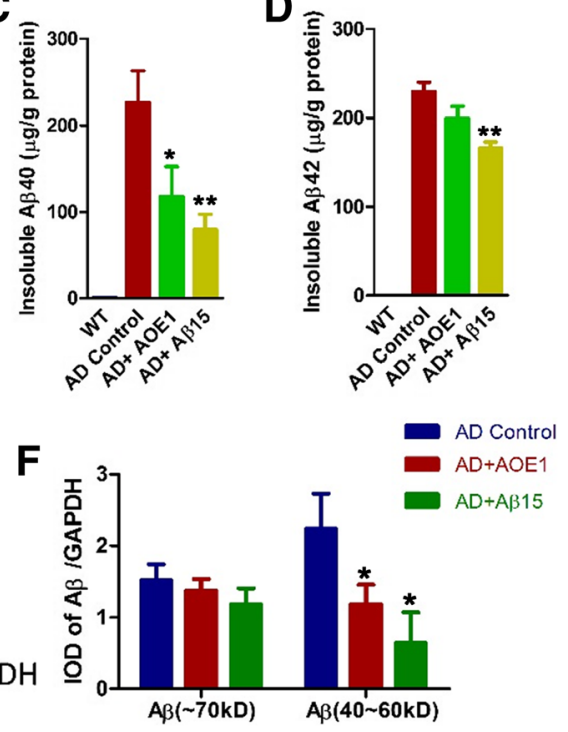

Fig. 6 EBY100-L2 (AOE1) immunization reduced $\beta$-amyloid peptide (A $\beta$ ) levels in the brains of Alzheimer's disease (AD) mice. After the behavior test, the mouse brain homogenate was prepared by using radioimmunoprecipitation assay buffer (soluble fraction) and guanidinium chloride buffer (insoluble fraction), respectively. Soluble $(\mathbf{a}, \mathbf{b})$ and insoluble $(\mathbf{c}, \mathbf{d}) A \beta_{40}(\mathbf{a}, \mathbf{c})$ and $A \beta_{42}(\mathbf{b}$, d) were determined using an $A \beta$ enzyme-linked immunosorbent assay kit (a-d) (compared with $A D$ control, ${ }^{*} p<0.05,{ }^{* *} p<0.01$ ). e The A $\beta$ oligomer levels in the brain extracts of mice immunized with or without AOE1 were detected by Western blot analysis, and the band density was quantified using IpWin5 software (f) (compared with AD control, * $p<0.05$ ). GAPDH Glyceraldehyde 3-phosphate dehydrogenase, WT Wild type, IOD Integrated optical density

positive control. PMA/ionomycin increased the production of IFN- $\gamma$ and IL- 4 by the splenocytes of AD mice immunized with both AOE1 vaccine and EBY100 yeast cells (Fig. $8 \mathrm{a}$ and b). However, restimulation by $\mathrm{A} \beta_{42}$ or L2 did not induce the increased secretion of IFN- $\gamma$ and IL-4 in the splenocytes. These results indicated that AOE1 vaccination did not induce an $\mathrm{A} \beta$-specific $\mathrm{T}$-cell response.

Another side effect induced by previous $A \beta$ vaccine is microhemorrhages [32]. To assess the microhemorrhages induced by $A O E 1$ and $A \beta_{15}$ vaccination, we stained brain sections with Prussian blue stain. Like AD control and WT mice, AOE1-immunized AD mice displayed rare microhemorrhages in the brain slides, whereas more microhemorrhages were observed in $A \beta_{15}$-immunized AD mice. These results suggested that AOE1 might be a safer vaccine than $A \beta_{15}$.

The effects of AOE1 or $\mathrm{A} \beta_{15}$ immunization on synaptic pathology in AD mice were assessed by immunostaining with antisynaptophysin antibodies (Fig. 8d). APP/PS1 control mice showed a significant decrease in synaptophysin fluorescence in the cortex and hippocampus, whereas immunization with AOE1 or $\mathrm{A} \beta_{15}$ significantly increased synaptophysin levels, indicating that AOE1-mediated $A \beta$ oligomer clearance reduced synaptic pathology.

\section{Discussion}

A $\beta$ immunotherapy including active immunization with $\mathrm{A} \beta$ and passive immunization with anti-A $\beta$ antibodies for $\mathrm{AD}$ treatment has been investigated for almost 2 decades [10]. However, none of the $A \beta$ vaccines or antibodies were successfully developed to rescue the memory deficits of patients with AD in phase III clinical trials [32, 33]. The first-generation $A \beta$ vaccine AN1792 was terminated in phase II clinical trials because of serious A $\beta$-specific T-cell reactions. To overcome this side effect, the second-generation $A \beta$ vaccines, such as CAD-106, ACC-001, ACI-24, and MER5101, applied the N-terminal fragments of $A \beta_{42}$ as immunogens [13, 34-36]. These vaccines elicited antibodies against $A \beta$ monomers, oligomers, fibrils, and APP, but they still induced side effects such as cephaledema, autoimmune reactions and inhibition of the physiological functions of $A \beta$ monomer and APP. Moreover, the therapeutic effects of the antibodies induced by the vaccines could be reduced by APP or A $\beta$ monomer-induced neutralization [37, 38]. An increasing body of evidence indicates that $\mathrm{A} \beta$ oligomers play a key role in neuronal dysfunction and development of $\mathrm{AD}$ [39-41], whereas A $\beta$ monomer and APP are involved in the development and plasticity of the nervous system and contribute to cognitive performance and memory [42]. A vaccine or antibody that specifically targets $A \beta$ oligomers but not A $\beta$ monomer or APP may have better therapeutic potential [39]. Recently, an A $\beta O$ monoclonal antibody produced by Biogen, aducanumab, reduced $A \beta$ levels in the brain and slowed the clinical recognition decline of patients with AD [4], implying that the specificity of antibodies for $A \beta$ oligomers is important for the development of AD therapeutics. 

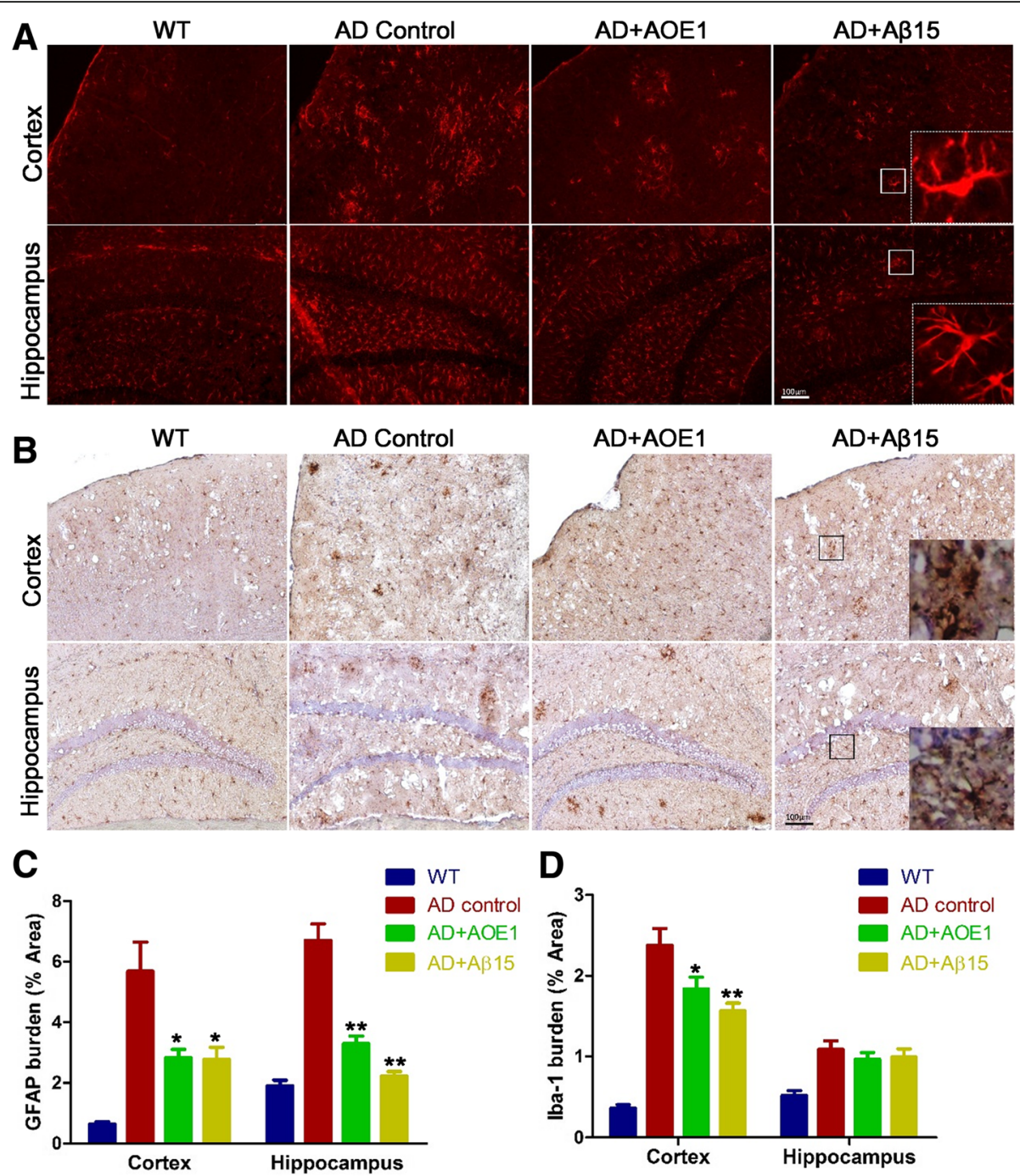

Fig. 7 EBY100-L2 (AOE1) vaccination decreased activated astrocytes and microglia in the hippocampus and cortex of Alzheimer's disease (AD) mice. a Astrocytes in the cortex and hippocampus of brain slices were determined by immunohistochemistry (IHC) using glial fibrillary acidic protein (GFAP) monoclonal antibody, and then the stained astrocytes were quantified using IpWin5 software (c) (compared with AD control, $\left.{ }^{*} p<0.05,{ }^{* *} p<0.01\right)$. b Microglia in the cortex and hippocampus of brain slices were detected by IHC using ionized calcium-binding adaptor molecule-1 (Iba-1) polyclonal antibody, and then the stained microglia were quantified using IpWin5 software (d) (compared with AD control, $\left.{ }^{*} p<0.05,{ }^{* *} p<0.01\right)$. A $\beta \beta$-Amyloid peptide, WT Wild type

To imitate the epitope of $A \beta$ oligomers, $A B r i$ and $3 A$ vaccines were developed. $A B r i$ is a peptide that has no sequence homology to $A \beta$ or other human proteins and induces British amyloidosis. Its polymerized forms may simulate the conformational structures of $A \beta$ oligomers and induce antibodies against $A \beta$ oligomers [43]. 3A, a peptide with a nonhuman random sequence, may aggregate to oligomers that mimic $A \beta$ oligomers and elicit antibodies recognizing $A \beta$ oligomers [44]. Like $A \beta$, ABri and $3 \mathrm{~A}$ themselves are not epitopes of $\mathrm{A} \beta$ oligomers and may form oligomeric mimotopes only after aggregation. However, the titer of antioligomer antibodies induced by these two vaccines did not easily reach the desired levels, because the immunogenicity of the formed mimotopes could not be readily improved by carriers. AD02 was another vaccine targeting $A \beta$ aggregates. It was composed of keyhole limpet hemocyanin (KLH) and an epitope peptide simulating the conformation of the $A \beta_{1-6}$ fragment. However, AD02-induced antibodies specifically recognized $A \beta$ fibrils rather than $A \beta$ oligomers, which may limit its therapeutic potential [39].

$A \beta$ oligomers generally exist in varied forms with a wide range of molecular weights and are unstable in solution [45, 46], which brings enormous difficulties to obtaining the oligomer-specific epitopes. In the present study, we first obtained a series of peptides that simulated the specific epitopes of $A \beta$ oligomers by screening the random 12-peptide libraries using IVIG-A $\beta \mathrm{O}$ as 


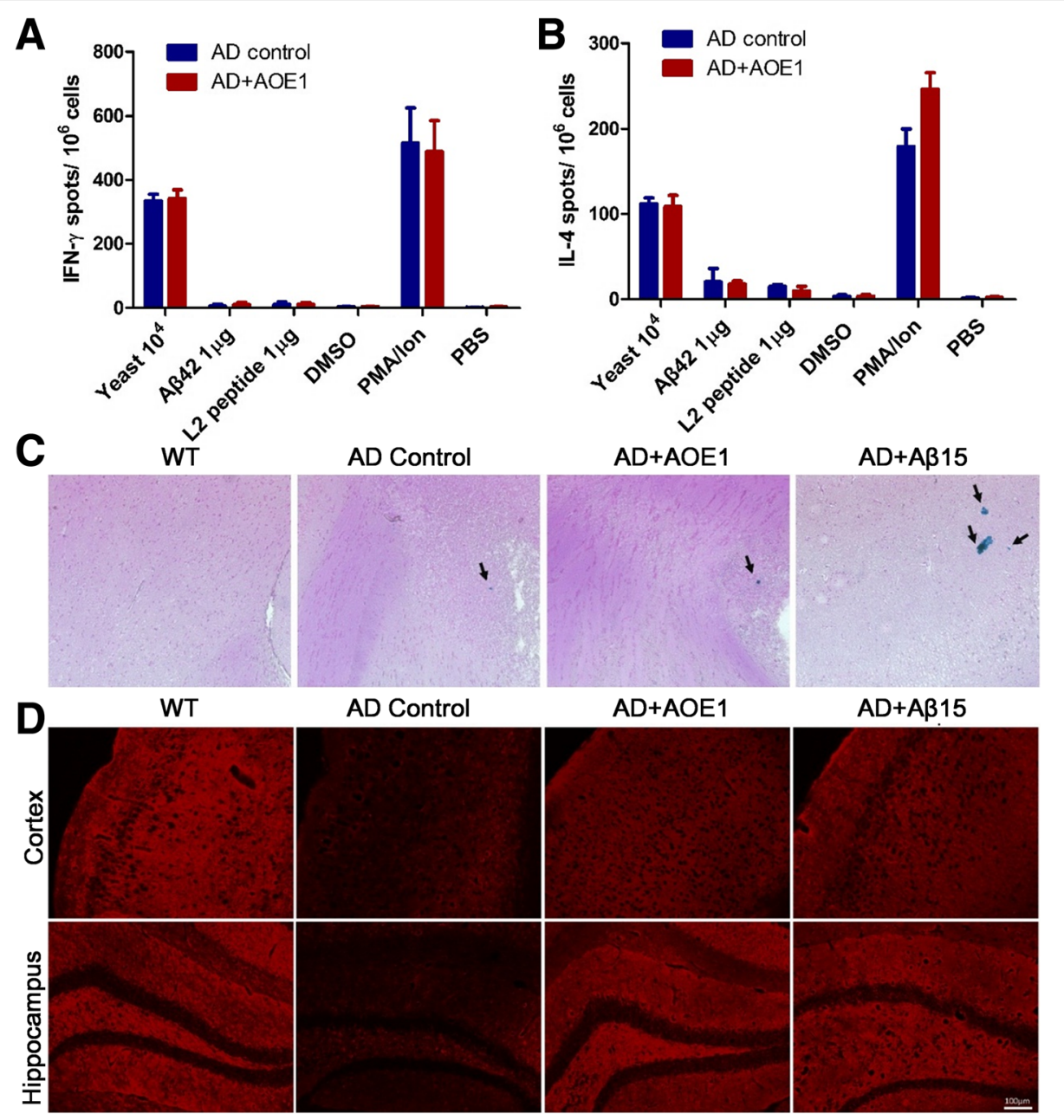

Fig. 8 EBY100-L2 (AOE1) immunization does not activate $\beta$-amyloid peptide (Aß)-reactive T cells and rarely induces microhemorrhages. T-cell activation in Alzheimer's disease (AD) mice vaccinated with AOE1 was detected by enzyme-linked immunospot (ELISPOT) assay. The spleen cells were obtained from the $A D$ mice vaccinated with $A O E 1$ and restimulated with yeast carrier, $A \beta_{42}, A O E 1$ epitope peptides, and phorbol 12-myristate 13-acetate (PMA)/ionomycin (positive stimulator) as well as with dimethyl sulfoxide (DMSO) and PBS (negative control). The secretion of interferon (IFN)- $\gamma$ (a) and interleukin (IL)-4 (b) were determined by ELISPOT assay. c, Microhemorrhages in the brain slices were determined through Prussian blue staining. Rare microhemorrhages were observed in the brains of mice vaccinated with AOE1. Arrows indicate microhemorrhage spots. d The synaptic pathology in the cortex and hippocampus of brain slices was determined through immunohistochemistry using antisynaptophysin antibody. WT Wild type

target proteins. Twenty peptides were isolated, and eight were expressed on the surface of EBY100 S. cerevisiae and immunized C57BL/6 mice. All eight vaccines elicited antibodies against the epitope peptides, but only one candidate, AOE1 with L2 peptide as a mimotope, elicited oligomer-specific antibodies. Moreover, when expressed on hepatitis B core-based virus-like particles or chemically conjugated to KLH, L2 still did not induce antibodies against $A \beta$ oligomer, suggesting that both L2 and yeast EBY100 contributed the formation of simulated conformation of the mimotope. These results demonstrated that although the eight synthetic epitope peptides bound to IVIG-A $\beta O$ in vitro and the induced antibodies bound to mimotopes themselves at high titers, the most expressed epitope on the carrier did not simulate the conformation of the epitope peptides. Therefore, it is very difficult for the epitope peptides to simulate a spatial three-dimensional conformation of oligomer, which may be a main barrier for the development of amyloid conformation-specific vaccine. Fortunately, we happened to obtain AOE1, which induced generation of antibodies against $A \beta$ oligomer. In a strict way, AOE1 vaccine is the first vaccine prepared by the mimotope of $A \beta$ oligomers. AOE1 attenuated the cognitive dysfunction of APP/PS1 transgenic mice by reducing $A \beta$ burden, especially $A \beta$ oligomers with the molecular size of $40-60 \mathrm{kDa}$, including a $56 \mathrm{kDa}$ soluble $\mathrm{A} \beta$ oligomer $\left(A \beta^{*} 56\right)$ that impaired long-lasting synaptic plasticity 
and disrupted cognition independently of neuron loss or plaque deposition in AD [47]. Although the titers of anti-A $\beta$ oligomer antibodies induced by AOE1 were not very high, AOE1 immunization still exhibited a remarkably therapeutic effect, which may be due to the behavioral improvement of $\mathrm{AD}$ mice being closely linked to the reduction of $A \beta$ oligomers rather than amyloid plaques or overall $A \beta$ levels [48].

Neuroinflammation induced by microglia and astrocytes is associated with the pathogenesis of $\operatorname{AD}[49,50]$. $A \beta$ oligomers are critical initial factors in activating the microglia and astrocytes to release inflammatory factors and amplify neurodegeneration [51, 52]. In the present study, AOE1 vaccine significantly decreased the activation of astrocytes and microglia in the hippocampus and cortex of $\mathrm{AD}$ transgenic mice and may have partly contributed to the attenuation of $\mathrm{AD}$ pathologies and cognitive deficits. The side effect induced by A $\beta$-specific T-cell reactions has been one obstacle in the development of $\mathrm{AD}$ therapeutic vaccines. In this work, AOE1 did not activate $\mathrm{A} \beta$-specific $\mathrm{T}$ cells or induce microhemorrhage, discarding the disadvantages of previous $A \beta$ vaccines. Like other vaccines with yeast as a carrier, AOE1 was characterized by easy preparation, good safety, and low cost [53, 54], suggesting that AOE1 holds potential promise for $\mathrm{AD}$ treatment.

\section{Conclusions}

We generated a novel vaccine, AOE1, with an $A \beta$ oligomer-specific mimotope that could induce antibodies with high specificity to $A \beta$ oligomers. AOE1 immunization attenuated $A \beta$ pathologies and cognitive deficits in transgenic mice with $\mathrm{AD}$, decreased the overactivation of glial cells, and did not induce microhemorrhage in the brains of $\mathrm{AD}$ mice. These findings suggest that AOE1 may be a safer and more effective vaccine for the treatment of $\mathrm{AD}$ than the ones developed to date.

\section{Abbreviations}

$A \beta$ : $\beta$-Amyloid peptide; A $A O$ : $\beta$-Amyloid peptide oligomer-specific antibodies; AD: Alzheimer's disease; APP: Amyloid precursor protein; DMSO: Dimethyl sulfoxide; DTT: Dithiothreitol; ECL: Enhanced chemiluminescence; ELISA: Enzyme-linked immunosorbent assay; ELISPOT: Enzyme-linked immunospot; FITC: Fluorescein isothiocyanate; GFAP: Glial fibrillary acidic protein; HFIP: Hexafluoroisopropanol; Iba-1: Ionized calcium-binding adaptor molecule-1; IFN- $\gamma$ : Interferon- $\gamma$; IgG: Immunoglobulin G; IHC: Immunohistochemistry; IL-4: Interleukin 4; IOD: Integrated optical density; ITI: Intertrial interval; IVIG: Intravenous immunoglobulin G; KLH: Keyhole limpet hemocyanin; NC: Nitrocellulose; NOR: Novel object recognition; OD: Optical density; PBST: PBS with Tween-20; PMA: Phorbol 12-myristate 13-acetate; RIPA: Radioimmunoprecipitation assay; RT: Room temperature; ThS: Thioflavin S; WT: Wild type

\section{Acknowledgements}

This study was supported by the National Natural Science Foundation of China (grants 81371208, 31471720, 31101335) and the National Science and Technology Major Projects of New Drugs (grants 2012ZX09103301-001, 2014ZX09102045-006).
Availability of data and materials

Not applicable.

\section{Authors' contributions}

RL designed the study and revised the manuscript. SW carried out the experiments involving mimotope screening, performed the statistical analysis, and wrote the manuscript. DL participated in the design of the study and helped to draft the manuscript. LZ participated in the design of the study, helped to perform the statistical analysis, and revised the manuscript. MJ participated in experiments involving mimotope screening and biochemical analysis. YZ participated in the biochemical and histochemical analyses. QD participated in the biochemical and histochemical analyses. SL participated in the behavioral tests. XX helped to design the study and revised the manuscript. All authors read and approved the final manuscript.

\section{Competing interests}

The authors declare that they have no competing interests.

\section{Consent for publication}

Not applicable.

\section{Ethics approval}

The animal treatment, husbandry, and experimental protocols of the present study received the approval of the Tsinghua University Animal Care and Use Committee (reference number 15-LRT1). Experiments were performed according to the code of practice for animal experimentation of the U.S. Animal Welfare Act and the Public Health Service Policy on Humane Care and Use of Laboratory Animals of the National Institutes of Health.

\section{Publisher's Note}

Springer Nature remains neutral with regard to jurisdictional claims in published maps and institutional affiliations.

\section{Author details}

${ }^{1}$ National Key Laboratory of Biochemical Engineering, Institute of Process Engineering, Chinese Academy of Sciences, Haidian District, Beijing 100190, China. ${ }^{2}$ School of Life Science, Anhui Agricultural University, Hefei 230036,

China. ${ }^{3}$ School of Life Science, Ningxia University, Yinchuan 750021, China.

Received: 28 February 2017 Accepted: 22 May 2017

Published online: 07 June 2017

\section{References}

1. Scheltens P, Blennow K, Breteler MMB, de Strooper B, Frisoni GB, Salloway S, et al. Alzheimer's disease. Lancet. 2016;388:505-17.

2. Querfurth HW, LaFerla FM. Alzheimer's disease. N Engl J Med. 2010;362:329-44. A published erratum appears in N Engl J Med. 2011;364:588.

3. Karran E, Mercken M, De Strooper B. The amyloid cascade hypothesis for Alzheimer's disease: an appraisal for the development of therapeutics. Nat Rev Drug Discov. 2011;10:698-712.

4. Sevigny J, Chiao P, Bussière T, Weinreb PH, Williams L, Maier M, et al. The antibody aducanumab reduces $A \beta$ plaques in Alzheimer's disease. Nature. 2016;537:50-6.

5. Haass C, Selkoe DJ. Soluble protein oligomers in neurodegeneration: lessons from the Alzheimer's amyloid $\beta$-peptide. Nat Rev Mol Cell Biol. 2007;8:101-12.

6. Müller UC, Zheng H. Physiological functions of APP family proteins. Cold Spring Harb Perspect Med. 2012;2:a006288.

7. Kamenetz F, Tomita T, Hsieh H, Seabrook G, Borchelt D, Iwatsubo T, et al. APP processing and synaptic function. Neuron. 2003:37:925-37.

8. Kayed R, Head E, Thompson JL, McIntire TM, Milton SC, Cotman CW, et al. Common structure of soluble amyloid oligomers implies common mechanism of pathogenesis. Science. 2003;300:486-9.

9. Schneeberger A, Mandler M, Mattner F, Schmidt W. AFFITOME ${ }^{\oplus}$ technology in neurodegenerative diseases: the doubling advantage. Hum Vaccin. 2010;6:948-52.

10. Schenk D, Barbour R, Dunn W, Gordon G, Grajeda H, Guido T, et al. Immunization with amyloid- $\beta$ attenuates Alzheimer-disease-like pathology in the PDAPP mouse. Nature. 1999:400:173-7.

11. Gilman S, Koller M, Black RS, Jenkins L, Griffith SG, Fox NC, et al. Clinical effects of $A B$ immunization (AN1792) in patients with $A D$ in an interrupted trial. Neurology. 2005;64:1553-62. 
12. Lemere CA, Masliah E. Can Alzheimer disease be prevented by amyloid- $\beta$ immunotherapy? Nat Rev Neurol. 2010;6:108-19.

13. Wiessner C, Wiederhold KH, Tissot AC, Frey P, Danner S, Jacobson LH, et al. The second-generation active $A \beta$ immunotherapy CAD106 reduces amyloid accumulation in APP transgenic mice while minimizing potential side effects. J Neurosci. 2011;31:9323-31.

14. Liu B, Frost JL, Sun J, Fu H, Grimes S, Blackburn P, et al. MER5101, a novel $A \beta 1-15: D T$ conjugate vaccine, generates a robust anti-A $\beta$ antibody response and attenuates $A \beta$ pathology and cognitive deficits in APPswe/PS1 $\triangle E 9$ transgenic mice. J Neurosci. 2013:33:7027-37.

15. Davtyan H, Ghochikyan A, Petrushina I, Hovakimyan A, Davtyan A, Poghosyan A, et al. Immunogenicity, efficacy, safety, and mechanism of action of epitope vaccine (Lu AF20513) for Alzheimer's disease: prelude to a clinical trial. J Neurosci. 2013;33:4923-34.

16. Pasquier F, Sadowsky C, Holstein A, Leterme GLP, Peng $Y$, Jackson N, et al. Two phase 2 multiple ascending-dose studies of vanutide cridificar (ACC-001) and QS-21 adjuvant in mild-to-moderate Alzheimer's disease. J Alzheimers Dis. 2016:51:1131-43.

17. Farlow MR, Andreasen N, Riviere ME, Vostiar I, Vitaliti A, Sovago J, et al. Long-term treatment with active A $\beta$ immunotherapy with CAD106 in mild Alzheimer's disease. Alzheimers Res Ther. 2015;7:23.

18. Delrieu J, Ousset PJ, Caillaud C, Vellas B. 'Clinical trials in Alzheimer's disease': immunotherapy approaches. J Neurochem. 2012;120 Suppl 1:186-93.

19. Vandenberghe R, Rinne JO, Boada M, Katayama S, Scheltens P, Vellas B, et al. Bapineuzumab for mild to moderate Alzheimer's disease in two global, randomized, phase 3 trials. Alzheimers Res Ther. 2016;8:18.

20. Doody RS, Thomas RG, Farlow M, Iwatsubo T, Vellas B, Joffe S, et al. Phase 3 trials of solanezumab for mild-to-moderate Alzheimer's disease. N Engl J Med. 2014;370:311-21.

21. Relkin N. Clinical trials of intravenous immunoglobulin for Alzheimer's disease. J Clin Immunol. 2014;34 Suppl 1:S74-9.

22. Hyman BT, Smith C, Buldyrev I, Whelan C, Brown H, Tang MX, et al. Autoantibodies to amyloid- $\beta$ and Alzheimer's disease. Ann Neurol. 2001;49:808-10.

23. Wang T, Xie XX, Ji M, Wang SW, Zha J, Zhou WW, et al. Naturally occurring autoantibodies against $A \beta$ oligomers exhibited more beneficial effects in the treatment of mouse model of Alzheimer's disease than intravenous immunoglobulin. Neuropharmacology. 2016;105:561-76.

24. Yang SG, Wang SW, Zhao M, Zhang R, Zhou WW, Li YN, et al. A peptide binding to the $\beta$-site of APP improves spatial memory and attenuates AB burden in Alzheimer's disease transgenic mice. PLoS One. 2012;7:e48540.

25. Chao G, Lau WL, Hackel BJ, Sazinsky SL, Lippow SM, Wittrup KD. Isolating and engineering human antibodies using yeast surface display. Nat Protoc 2006;1:755-68.

26. Srivastava V, Yang Z, Hung IFN, Xu J, Zheng B, Zhang MY. Identification of dominant antibody-dependent cell-mediated cytotoxicity epitopes on the hemagglutinin antigen of pandemic H1N1 influenza virus. J Virol. 2013;87:5831-40.

27. Antunes M, Biala G. The novel object recognition memory: neurobiology, test procedure, and its modifications. Cogn Process. 2012;13:93-110.

28. Zhou WW, Lu S, Su YJ, Xue D, Yu XL, Wang SW, et al. Decreasing oxidative stress and neuroinflammation with a multifunctional peptide rescues memory deficits in mice with Alzheimer disease. Free Radic Biol Med. 2014;74:50-63.

29. Rak M, Del Bigio MR, Mai S, Westaway D, Gough KM. Dense-core and diffuse $A \beta$ plaques in TgCRND8 mice studied with synchrotron FTIR microspectroscopy. Biopolymers. 2007:87:207-17.

30. Jongbloed W, Bruggink KA, Kester MI, Visser PJ, Scheltens P, Blankenstein MA, et al. Amyloid- $\beta$ oligomers relate to cognitive decline in Alzheimer's disease. Alzheimers Dis. 2015;45:35-43.

31. Chatila T, Silverman L, Miller R, Geha R. Mechanisms of T cell activation by the calcium ionophore ionomycin. J Immunol. 1989;143:1283-9.

32. Wilcock DM, Colton CA. Immunotherapy, vascular pathology, and microhemorrhages in transgenic mice. CNS Neurol Disord Drug Targets. 2009;8:50-64.

33. Jindal H, Bhatt B, Sk S, Malik JS. Alzheimer disease immunotherapeutics: then and now. Hum Vaccines Immunother. 2014;10:2741-3.

34. Lannfelt $L$, Relkin NR, Siemers ER. Amyloid- $\beta$-directed immunotherapy for Alzheimer's disease. J Intern Med. 2014;275:284-95.

35. Arai H, Suzuki H, Yoshiyama T. Vanutide cridificar and the QS-21 adjuvant in Japanese subjects with mild to moderate Alzheimer's disease: results from two phase 2 studies. Curr Alzheimer Res. 2015;12:242-54.
36. Wang CY, Finstad CL, Walfield AM, Sia C, Sokoll KK, Chang TY, et al. Site-specific UBITh ${ }^{\oplus}$ amyloid- $\beta$ vaccine for immunotherapy of Alzheimer's disease. Vaccine. 2007; $25: 3041-52$

37. Bin L, Jeffrey LF, Jing S, Hongjun F, Stephen G, Peter B, et al. MER5101, a novel $A \beta 1-15: D T$ conjugate vaccine, generates a robust anti-A $\beta$ antibody response and attenuates $A \beta$ pathology and cognitive deficits in APPswe/ PS1E9 transgenic mice. J Neurosci. 2013;33:7027-37.

38. Soscia SJ, Kirby JE, Washicosky KJ, Tucker SM, Ingelsson M, Hyman B, et al. The Alzheimer's disease-associated amyloid $\beta$-protein is an antimicrobial peptide. PLoS One. 2010;5:e9505.

39. Mandler M, Santic R, Gruber P, Cinar Y, Pichler D, Funke SA, et al. Tailoring the antibody response to aggregated $A \beta$ using novel Alzheimer-vaccines. PLoS One. 2015;10:e011523.

40. Xia W, Yang T, Shankar G, Smith IM, Shen Y, Walsh DM, et al. A specific enzyme-linked immunosorbent assay for measuring $\beta$-amyloid protein oligomers in human plasma and brain tissue of patients with Alzheimer disease. Arch Neurol. 2009;66:190-9.

41. Benilova I, Karran E, De Strooper B. The toxic A $\beta$ oligomer and Alzheimer's disease: an emperor in need of clothes. Nat Neurosci. 2012;15:349-57.

42. Wild K, August A, Pietrzik CU, Kins S. Structure and synaptic function of metal binding to the amyloid precursor protein and its proteolytic fragments. Front Mol Neurosci. 2017;10:21.

43. Goñi F, Prelli F, Ji Y, Scholtzova H, Yang J, Sun Y, et al. Immunomodulation targeting abnormal protein conformation reduces pathology in a mouse model of Alzheimer's disease. PLoS One. 2010;5:e13391.

44. Rasool S, Albay R, Martinez-Coria H, Breydo L, Wu J, Milton S, et al. Vaccination with a non-human random sequence amyloid oligomer mimic results in improved cognitive function and reduced plaque deposition and micro hemorrhage in Tg2576 mice. Mol Neurodegener. 2012;7:37.

45. Nichols MR, Colvin BA, Hood EA, Paranjape GS, Osborn DC, Terrill-Usery SE. Biophysical comparison of soluble amyloid- $\beta(1-42)$ protofibrils, oligomers, and protofilaments. Biochemistry. 2015;54:2193-204.

46. Hayden EY, Conovaloff JL, Mason A, Bitan G, Teplow DB. Preparation of pure populations of covalently stabilized amyloid $\beta$-protein oligomers of specific sizes. Anal Biochem. 2017:518:78-85.

47. Lesné $\mathrm{S}$, Koh MT, Kotilinek L, Kayed R, Glabe CG, Yang A, et al. A specific amyloid- $\beta$ protein assembly in the brain impairs memory. Nature. 2006;440:352-7

48. Asuni AA, Boutajangout A, Scholtzova H, Knudsen E, Li YS, Quartermain D, et al. Vaccination of Alzheimer's model mice with $A \beta$ derivative in alum adjuvant reduces $A \beta$ burden without microhemorrhages. Eur J Neurosci. 2006;24:2530-42.

49. Streit WJ. Microglial activation and neuroinflammation in Alzheimer's disease: a critical examination of recent history. Front Aging Neurosci. 2010;2:22.

50. Streit WJ, Mrak RE, Griffin WST. Microglia and neuroinflammation: a pathological perspective. J Neuroinflammation. 2004;1:4.

51. Sondag CM, Dhawan G, Combs CK. $\beta$ Amyloid oligomers and fibrils stimulate differential activation of primary microglia. J Neuroinflammation. 2009;6:1.

52. Bodani RU, Sengupta U, Castillo-Carranza DL, Guerrero-Muñoz MJ, Gerson JE, Rudra J, et al. Antibody against small aggregated peptide specifically recognizes toxic A $\beta-42$ oligomers in Alzheimer's disease. ACS Chem Neurosci. 2015;6:1981-9.

53. Stubbs AC, Martin KS, Coeshott C, Skaates SV, Kuritzkes DR, Bellgrau D, et al. Whole recombinant yeast vaccine activates dendritic cells and elicits protective cell-mediated immunity. Nat Med. 2001;7:625-9.

54. Ardiani A, Higgins JP, Hodge JW. Vaccines based on whole recombinant Saccharomyces cerevisiae cells. FEMS Yeast Res. 2010;10:1060-9. 